Saint Louis University School of Law

Scholarship Commons

All Faculty Scholarship

2020

The Americans with Disabilities Act and Healthcare Employer-

Mandated Vaccinations

Y. Tony Yang

Elizabeth Pendo

Dorit Rubinstein Reiss

Follow this and additional works at: https://scholarship.law.slu.edu/faculty

Part of the Disability Law Commons, Health Law and Policy Commons, and the Therapeutics Commons 


\section{S A I N T L O U IS \\ $\begin{array}{llllllllll}U & N & \text { I } & V & E & R & S & \text { I } & T & Y\end{array}$ \\ SCHOOL OF LAW}

\section{SAINT LOUIS UNIVERSITY SCHOOL OF LAW Legal Studies Research Paper Series}

No. $2020-12$

The Americans with Disabilities Act and Healthcare EmployerMandated Vaccinations

Y. Tony Yang

George Washington University

Elizabeth Pendo

Saint Louis University - School of Law

Dorit Rubinstein Reiss

University of California Hastings College of the Law

38(16) Vaccine 3184 (Apr. 3, 2020)

UC Hastings Research Paper No. 390 


\title{
The Americans with Disabilities Act and Healthcare Employer-Mandated Vaccinations
}

38(16) Vaccine 3184 (Apr. 3, 2020)

UC Hastings Research Paper No. 390

\author{
Y. Tony Yang \\ George Washington University \\ Elizabeth Pendo \\ Saint Louis University - School of Law \\ Dorit Rubinstein Reiss \\ University of California Hastings College of the Law
}

Date Written: April 3, 2020

\begin{abstract}
$\underline{\text { Abstract }}$
Battles around workplace vaccination policies often focus on the annual influenza vaccine, but many healthcare employers impose requirements for additional vaccines because of the increased likelihood that employees in this sector will interact with populations at increased risk of acquiring or experiencing harmful sequelae of vaccine-preventable diseases. The federal Centers for Disease Control and Prevention and many states recommend healthcare employees receive numerous vaccines, including measles, mumps, and rubella ("MMR"); tetanus, diphtheria, and pertussis ("Tdap"). However, recent outbreaks of once-eliminated diseases that are now resurgent and the rising antivaccination movement raise questions about how far employers can go to mandate vaccinations. While healthcare institutions are increasingly mandating that employees receive vaccinations, employee objections to vaccines, including litigation, have increased in recent years. Employer policies must comply with the Americans with Disabilities Act ("ADA"), which prohibits discrimination on the basis of disability. Although the ADA permits mandatory vaccine policies under certain circumstances, employers must consider reasonable accommodations, which are changes to the job or work environment that permit the employee with a disability to perform the essential functions of the job, within certain limits. This article analyzes two recent cases which suggest how employers seeking to protect their workforce and the patients they serve by requiring vaccines can work within the framework of the ADA to implement these policies.
\end{abstract}


Keywords: disability, Americans with Disabilities Act, vaccination policies, employment discrimination, reasonable accommodation, undue burden, direct threat, health care workplace

\section{Suggested Citation:}

Yang, Y. Tony and Pendo, Elizabeth and Reiss, Dorit Rubinstein, The Americans with Disabilities Act and Healthcare Employer-Mandated Vaccinations (April 3, 2020). 38(16) Vaccine 3184 (Apr. 3, 2020); UC Hastings Research Paper No. 390. 